\title{
GESTÃO BALANCEADA E PRÁTICAS DE GESTÃO: UM ESTUDO SOBRE SUAS INFLUENCIAS NO DESEMPENHO FINANCEIRO
}

\section{BALANCED MANAGEMENT AND MANAGEMENT PRACTICES: A STUDY OF THEIR INFLUENCES ON FINANCIAL PERFORMANCE}

\begin{abstract}
Djair Picchiai ${ }^{1}$
Anderson Queiroz Lemos ${ }^{2}$

Recebido em: 16/11/2016 Aceito em: 30/03/2017 djair.picchiai@fgv.br

Resumo: O conceito de gestão balanceada (aquela simultaneamente alinhada, coerente e consistente) é apresentado neste ensaio como uma capacidade organizacional que antecede as práticas de gestão no alcance do desempenho financeiro. Pela abordagem da ResourceBased View (RBV) as empresas se diferenciam pelos recursos e capacidades possuídos, mas as restrições dos mesmos impedem-nas de terem o desempenho esperado. Esta pesquisa propõe que as práticas de gestão gerarão efeito positivo sobre o desempenho financeiro se forem antecedidas por uma gestão que balanceie estratégias, estrutura e competências organizacionais. Do ponto de vista teórico, o ensaio insere o conceito de gestão balanceada na linha da estratégia como sendo uma capacidade organizacional.
\end{abstract}

Palavras-chave: Práticas de gestão. Gestão balanceada. Desempenho financeiro.

Abstract: The concept of balanced management (that simultaneously aligned, coherent and consistent) is used here as an organizational capability that predates management practices in achieving financial performance. By using Resource-Based View (RBV) approach firms differentiate themselves by the resources and capabilities possessed, but this restrictions prevent them from having the expected performance. The proposition elaborated for this theoretical essay is that management practices will generate greater effect on financial performance, only if the company has a balanced management among their strategies, structure and organizational skills. From a theoretical point of view, the article places the concept of balanced management in line with the strategy as an organizational capacity.

Keywords: Management practices. Management balanced. Financial performance.

\footnotetext{
${ }^{1}$ Escola de Administração de Empresas de São Paulo - FGV-EAESP - São Paulo - São Paulo - Brasil.

Faculdade Campo Limpo Paulista - FACCAMP - Campo Limpo Paulista - São Paulo - Brasil.

${ }^{2}$ Universidade Federal de Goiás - UFG - Jataí - Goiás - Brasil.
} 


\section{INTRODUÇÂO}

Para sobreviverem nos mercados cada vez mais competitivos, as empresas precisam de práticas de gestão que contribuam no alcance dos objetivos organizacionais. Nesses termos, muito esforço dos managers tem de ser gasto para fazer a organização funcionar de forma eficaz. Mas a verdade é que se muito tempo não for gasto para manter a eficiência das práticas organizacionais a empresa não sobreviverá (HOFER; SCHENDEL, 1978).

Assumindo que as práticas de gestão são recursos organizacionais, tem-se que se trata de uma condição necessária, mas não suficiente à geração de desempenho empresarial superior. Este ensaio propõe que as práticas de gestão e o esforço despendido pelos gestores para gerar e manter o equilíbrio da gestão organizacional são condições suficientes para a geração de desempenho financeiro superior. Para isso apresenta-se o conceito de gestão balanceada como uma capacidade desenvolvida dentro da empresa, pelo esforço dos gestores e que antecede a aplicação das práticas de gestão na geração de desempenho diferenciado.

Gestão balanceada é aquela que apresenta simultaneamente alinhamento, coerência e consistência nas relações entre estratégia, estrutura e competências organizacionais. Os conceitos de alinhamento, coerência e consistência estão ligados ao estudo da estratégia, de forma que o próprio planejamento estratégico requer alinhamento, coerência e consistência entre as estratégias, estrutura e competências organizacionais.

O modelo da Escola do Design (MINTZBERG; AHLSTRAND; LAMPEL, 2000) apresenta claramente o conceito de consistência, especialmente durante o processo de criação, avaliação e escolha da estratégia. Nesse modelo a estratégia não deve apresentar objetivos e nem políticas mutuamente inconsistentes. Sobre o alinhamento, Henderson e Venkatraman (1993) propuseram um modelo estratégico de alinhamento para conceituar e dirigir a gerência estratégica da Tecnologia da Informação (TI), sendo estes os primeiros autores a escreverem sobre a relação estreita entre estratégia de negócio e estratégia de TI. E a coerência significa a não contradição, ou seja, a relação no mesmo sentido entre as ideias das partes constituintes da organização.

A união dos três conceitos forma uma proxy, intitulada neste ensaio como sendo Gestão Balanceada. Sua aplicação no contexto da estratégia parece ser oportuna quando associada as práticas de gestão. As práticas de gestão muitas vezes resultam de técnicas de administração adaptadas e simplificadas das grandes empresas multinacionais, contudo, aquelas práticas inovadoras e importadas de qualquer natureza, em geral, só terão vida longa nas empresas em termos de uso, se cumprir a promessa de realizar melhores operações, promover custos reduzidos, maior velocidade e qualidade de processo (input - output), enfim, proporcionarem resultados melhores que os da concorrência.

O entendimento disto é que as práticas de gestão são recursos e sua correta utilização depende de escolhas. A escolha entre investir em recursos ou em estratégia já foi discutida na literatura em artigo publicado na Harvard Business Review em novembro de 1996 por Michael Porter. $\mathrm{Na}$ ocasião Porter alerta para a correta utilização da tomada de decisão entre investir em eficiência

Estudos do CEPE [ISSN 1982-6729]. Santa Cruz do Sul, n. 45, p. 35-51, jan./jun. 2017. https://online.unisc.br/seer/index.php/cepe/index 
operacional (recursos) ou no posicionamento de mercado (estratégia). Em outras palavras Porter fala do trade off entre ser prático ou estratégico.

Para desenvolver o argumento de que as práticas de gestão são recursos e que a gestão balanceada é uma capacidade organizacional, esse ensaio se posiciona dentro da abordagem teórica da RBV (Resource-Based View). Para Helfat e Peteraf (2003), uma firma tem capacidades organizacionais quando desempenha a coordenação de atividades diversas. Assim, um gerenciamento balanceado será uma capacidade interna à empresa quando o gestor combinar alinhamento, coerência e consistência, de forma que esse equilíbrio favoreça a aplicação das práticas de gestão no alcance do desempenho superior.

A literatura da RBV defende que as empresas não geram vantagem competitiva em virtude da sua limitada disponibilidade de recursos e capacidades. Entretanto, se todas as empresas num determinado setor de atividade tiverem as mesmas práticas de gestão, não haverá diferença de performance entre elas, a não ser que adotem estratégias diferentes. Isso significa que se admitirmos a gestão balanceada enquanto capacidade organizacional e as práticas de gestão enquanto recursos, as práticas de gestão serão condição necessária, mas não suficiente para geração de desempenho superior. Como a unidade de análise da RBV é a firma, a obtenção de desempenho superior vem por meio de uma gestão alinhada, coerente e consistente entre estratégia, estrutura e competências organizacionais.

A proposição desenvolvida para a pesquisa é que somente aquelas empresas que tiverem um gerenciamento interno devidamente balanceado com o desenho da estrutura, com o desenvolvimento das estratégias e das competências, possuirão práticas de gestão capazes de gerar efeito positivo sobre o desempenho financeiro.

A noção de que as firmas são heterogêneas em termos de capacidades e recursos têm estado no centro do campo do gerenciamento estratégico (PETERAF, 1993). As bases da literatura da RBV falam que para existir estratégia de crescimento da firma, ela deve explorar os recursos e as capacidades existentes além de desenvolver novas, ou ainda, adquiri-los do mercado (WERNERFELT, 1984). Como os mercados de fatores estratégicos são imperfeitos nem todos os recursos e capacidades estão disponíveis, assim a gestão balanceada é uma dessas capacidades que se desenvolve internamente a firma.

Apesar do pressuposto básico da RBV consistir na relação de causalidade entre vantagem competitiva e análise da escassez ou recursos disponíveis, a maior parte das pesquisas empíricas se concentra nos ativos tangíveis das firmas para demonstrar essa relação. Ademais, existe a ausência de um entendimento sobre de onde a heterogeneidade de recursos e capacidades vêm, sendo difícil para os pesquisadores explicarem ex anti como as empresas utilizam recursos e capacidades na geração de vantagem competitiva. Essa é uma lacuna ainda não completamente esclarecida nos estudos que abordam a RBV, tornando-a mais descritiva que prescritiva. Nestes termos, todos os esforços de pesquisa são na realidade uma forma de tentar preencher os gaps da RBV como proposta teórica.

Do ponto de vista prático a pesquisa é relevante, pois com o conceito de gestão balanceada as práticas de gestão sugeridas pelas firmas de consultoria e pelos manuais de pop management, só

Estudos do CEPE [ISSN 1982-6729]. Santa Cruz do Sul, n. 45, p. 35-51, jan./jun. 2017. https://online.unisc.br/seer/index.php/cepe/index 
criarão força para justificar sua aplicação se for analisado um passo anterior, que é verificar se a gestão da empresa cliente tem a capacidade de ser balanceada.

A estrutura do ensaio se desenvolve com a revisão da literatura da RBV, mormente sobre a importância das capacidades e dos recursos da firma. Em seguida é apresentado o modelo de gestão balanceada e os conceitos de alinhamento, coerência e consistência. Segue junto à construção da proposição da pesquisa. Por fim é feita uma sugestão de aplicação empírica ao ensaio.

\section{REFERENCIAL TEÓRICO}

$\mathrm{Na}$ estratégia empresarial o que motiva o pesquisador a trabalhar na fronteira do conhecimento, é a possibilidade de descoberta do que provoca melhor desempenho a uma empresa. Contudo, posicionar um argumento na literatura existente é provavelmente uma das maiores dificuldades em se elaborar um ensaio teórico. A questão é que esse posicionamento não somente define e limita a contribuição do argumento, como também determina tudo àquilo que não pode ser dito em função da literatura existente escolhida para posicionar o argumento (BARNEY, 2001). Nestes termos, as variáveis da pesquisa (capacidade organizacional e recurso) determinantes do desempenho superior são enquadradas na abordagem teórica da RBV.

\subsection{O papel das capacidades e dos recursos organizacionais no desempenho superior}

Entre as contribuições mais relevantes para o management sobre o que promove desempenho superior está a de Michael Porter, que analisou a competição sob o foco de posicionamento estratégico da firma num dado ambiente. Embora a unidade de análise de Porter em seus trabalhos não seja a firma, mas o grupo estratégico no ambiente em que este está competindo, uma importante contribuição à administração estratégica foi mostrar que tamanho e sorte ${ }^{3}$ não são as únicas características competitivas, ou seja, a empresa pode fazer mais coisas que isso para a geração de lucro acima da média.

Mas se as empresas estão submetidas a um mesmo ambiente competitivo, por que algumas apresentam desempenho superior que outras? Uma resposta genérica é porque elas fazem escolhas que as tornam mais eficientes (RUMELT; SCHENDEL; TEECE, 1991). Essa amplitude da resposta permite que os estudos sobre o que promove a vantagem competitiva possam analisados sobre diversas perspectivas.

Quando o foco é nos recursos e nas capacidades organizacionais, a abordagem utilizada é a Resourced Based View ${ }^{4}$ (RBV), que se desenvolveu a partir de Penrose (1959) e evoluiu no tempo com Wernerfelt (1984), Mahoney e Pandian (1992), Barney (1986), Barney (1991), Peteraf (1993), dentre vários outros.

\footnotetext{
${ }^{3}$ Excluindo a variável "sorte", que não pode ser controlada em testes estatísticos porque simplesmente compreende todos os efeitos que não podem ser previstos, o tamanho da firma pode ser mantido constante por meio de variáveis como por exemplo, número de funcionários e níveis hierárquicos, que por sinal definem a estrutura organizacional.

${ }^{4}$ Apesar de ter-se discutido bastante a questão da RBV apresentar em certo grau relações tautológicas, com a evolução dos conceitos de valor e raridade anteriormente desenvolvidos por Barney (1991) e criticados como causas da tautologia por Priem e Butler (2001), as definições atuais conseguem separar valor e desempenho.
}

Estudos do CEPE [ISSN 1982-6729]. Santa Cruz do Sul, n. 45, p. 35-51, jan./jun. 2017. https://online.unisc.br/seer/index.php/cepe/index 
Quando o foco é na capacidade de a empresa ter rotinas para muda-las rapidamente em ambientes de rápida mudança, a abordagem adequada é a Capacidade Dinâmica da firma, que teve origem nos trabalhos de Schumpeter (1942) e na década de 1980 institucionalizou-se nos estudos do gerenciamento estratégico com as contribuições de Dosi (1982), Prahalad e Hamel (1990), Teece, Pisano e Schuen (1997), Helfat e Peteraf (2003), dentre outros. Por fim, a eficiência pode ser estudada por meio dos Custos de Transação da firma, sob a ótica de que a eficiência vem com a economia na elaboração e cumprimento de contratos (COASE, 1937; WILLIAMSON, 1985; WILLIAMSON, 1991; LANGLOIS, 1992).

Como este ensaio defende que a gestão balanceada é uma capacidade organizacional, que se associa as práticas de gestão para a geração de efeito diferenciado sobre o desempenho financeiro, utilizou-se a RBV que é uma das principais abordagens da estratégia em nível de negócios no que concerne ao estudo da eficiência (WILLIAMSON, 1991).

A tradição das pesquisas baseadas em capacidades e recursos se desenvolveu a partir da contribuição de Selznick (1957) e Penrose (1959). Antes os recursos das firmas como terra, trabalho e capital eram tradicionalmente olhados na abordagem econômica tradicional Ricardiana (1817). A partir de então a firma é vista como um portfólio de capacidades, competências e recursos que se diferenciam das demais por causa da heterogeneidade.

A partir dessa mudança de paradigma, o papel do gestor como indivíduo responsável por promover a eficiência organizacional, tornou-se fundamental ao sucesso da firma. Segundo Kor e Maroney (2004, p. 2) citando Mahoney (1995), "o valor econômico que uma firma cria não deve ser pensado em termos da quantidade de recursos que possui, mas devido ao gerenciamento efetivo e inovativo de tais recursos".

Nessa mesma linha de pensamento, Wernerfelt (1984) entende que devido à amplitude da competição nos setores, o produto que é posto no mercado depende cada vez mais do recurso, assim, é necessário um comprometimento mínimo dos gestores com o desenvolvimento das capacidades e recursos da firma. Não restam duvidas que o papel dos gestores no desenvolvimento das capacidades é importante, mas para enquadrar gestão balanceada como capacidade organizacional, faz-se necessário uma definição do que esta venha a ser.

O termo gestão balanceada não é novo, uma vez que ele é recorrente nos estudos sobre análise de desempenho que usam a ferramenta gerencial Balanced ScoreCard. Segundo Rezende, Avila e Maia (2012), os estudos de Kaplan e Norton durante a década de 1990 e início dos anos 2000, tem relação com a busca por obtenção de padrão diferenciado de desempenho em longo prazo. Padrão este que seja capaz de materializar a estratégia e gerar valor consistentemente superior aos dos concorrentes, por meio da gestão balanceada da performance.

Para este ensaio gestão balanceada é uma proxy, de maneira que acessá-la depende do resultado dos esforços dos gestores na organização. Esse esforço em fazer a firma ser mais competitiva resulta numa gestão equilibrada nas relações entre a estrutura, as estratégias e as competências organizacionais, favorecendo assim, o alcance dos objetivos organizacionais.

Uma vez no mercado, as empresas fazem escolhas, inclusive sobre o desenho da estrutura organizacional, sistemas administrativos e estratégias para definir e coordenar os trabalhos

Estudos do CEPE [ISSN 1982-6729]. Santa Cruz do Sul, n. 45, p. 35-51, jan./jun. 2017. https://online.unisc.br/seer/index.php/cepe/index 
(RUMELT; SCHENDEL; TEECE, 1991). Essas escolhas devem estar integradas para que a firma alcance o sucesso.

Com efeito, estrutura, estratégias e competências organizacionais são aspectos organizacionais importantes e dependem da gestão balanceada. Segundo Chandler (1962), estratégia e estrutura são correlacionadas, e é na estrutura organizacional onde as estratégias são deliberadas pelos gestores e as decisões para o desenvolvimento das competências organizacionais são tomadas.

Como a uma combinação de atividades dá-se o nome de capacitações ou capacidades, a gestão balanceada também pode assim ser considerada, pois ela não é nada mais que o resultado da integração de esforços separados (para esse ensaio trata-se do esforço de combinar alinhamento, coerência e consistência) para o alcance dos objetivos organizacionais.

O termo capacidades flutua na literatura da mesma forma que um iceberg flutua no oceano gelado (DOSI; NELSON; WINTER, 2000), e isso permite o pesquisador ter certa flexibilidade no seu posicionamento. O conceito de capacidades é importante para esse ensaio por que recursos não terão valor por si só se não forem integrados deliberadamente pelo esforço do gestor na execução de atividades organizacionais. Isso significa que as práticas de gestão de uma empresa não terão valor por si só se não forem concebidas e aplicadas por uma gestão que seja alinhada, coerente e consistente com os objetivos organizacionais.

O conceito de capacidade adotado nesse ensaio não é o de Capacidades Dinâmicas proposto por Teece, Pisano e Schuen (1997), como sendo a habilidade da firma de integrar, construir e reconfigurar competências internas e externas para se adequar rapidamente as mudanças internas e externas. Embora ele seja construído sobre a base do conceito de Dosi, Nelson e Winter (2000), sobre a natureza e a dinâmica das capacidades organizacionais, onde a intencionalidade do gestor mais se manifesta.

O trabalho dos autores citados ajudou a montar um sentido de capacidade a este ensaio. Capacidade organizacional é aqui definida como um conjunto de ações intencionais que uma empresa é capaz de fazer tão bem com confiança e sucesso, derivada do esforço dos gestores de associar diferentes atividades organizacionais. Numa empresa, as capacidades geralmente são construídas em áreas funcionais específicas, se desenvolvendo com base nos recursos dessas áreas além da integração com os recursos de outras áreas.

Segundo Dosi, Nelson e Winter (2000), as capacidades de uma empresa preenchem o vazio entre a "intensão e resultado", ou seja, o resultado se torna um reflexo daquilo que foi intencionado, deliberado. Com efeito, se a gestão balanceada é uma ação intencional espera-se que o reflexo dessa ação incida sobre algo na organização, como sobre as suas práticas de gestão, por exemplo. Alguns exemplos de capacidade organizacional de empresas multinacionais são apresentados a seguir.

$\mathrm{Na}$ Eletronic Arts (EA), que é uma das mais bem-sucedida empresas de Vídeo Games do mundo, a cooperação entre as funções técnicas, comercial e de criação são um exemplo de capacidade (LEMOS E PICCHIAI, 2013). Segundo Hitt, Ireland e Hoskisson (2008), alguns observadores internacionais sugerem que a EA é capaz de combinar criatividade, normalmente

Estudos do CEPE [ISSN 1982-6729]. Santa Cruz do Sul, n. 45, p. 35-51, jan./jun. 2017. https://online.unisc.br/seer/index.php/cepe/index 
associada aos filmes de Hollywood, com sofisticação tecnológica, normalmente associada a empresas do Vale do Silício. Ela também é capaz de associar disciplina empresarial, normalmente associada às melhores empresas de manufatura do mundo.

Outro exemplo é a capacidade do Wal-Mart e da Dell na área de distribuição, pois elas utilizam de forma eficaz suas técnicas de gerenciamento de logística. Já na Sony o destaque é na área de fabricação, cuja capacidade é a miniaturização de componentes e produtos. Ou ainda a Microsoft na área de recursos humanos, que possuí a capacidade de motivar e reter funcionários (LEMOS E PICCHIAI, 2013).

Esses exemplos são suficientes para o entendimento de que são as capacidades e os recursos na perspectiva da RBV que tem o papel de proporcionar valor a firma (WERNERFELT, 1984). Tais capacidades tem relação com a forma com que as empresas se diferem, ou seja, quanto as suas atividades são específicas. Afinal, as heterogeneidades de capacidades e recursos num conjunto de empresas são uma das pedras fundamentais da RBV, e essa mesma heterogeneidade permite que firmas de várias capacidades compitam no mercado (PETERAF, 1993).

A abordagem da RBV entende que as empresas não geram vantagem competitiva em virtude da sua limitada disponibilidade de recursos e capacidades. Nesse sentido Wernerfelt (1984) explica que essas limitações as impedem de entrar num determinado mercado e restringem os níveis de lucro que obterão. Sendo assim, existe a possibilidade de que as empresas que possuam capacidades gerenciais suficientes tenham práticas de gestão influenciando de forma diferenciada no desempenho financeiro. Entende-se então a gestão balanceada como uma condição importante à geração de vantagem competitiva (Figura 1).

Como a abordagem teórica desse ensaio é a RBV, as capacidades e os recursos podem ser desenvolvidos internamente à firma. Sendo a gestão balanceada considerada uma capacidade organizacional, defende-se que ela não pode ser transferida a outra empresa nem copiada facilmente pela concorrência, o que gera a empresa uma condição importante para o desenvolvimento de práticas de gestão como fonte de desempenho diferenciado.

Figura 1 - Relação entre gestão balanceada, práticas de gestão, desempenho financeiro.

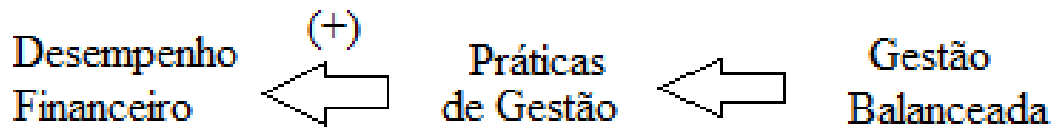

Fonte: Elaborada pelos autores.

Práticas de gestão (como por exemplo, introdução de técnicas de manufatura, acompanhamento constante do desempenho, gerenciamento, atração e retenção do capital humano, dentre outras) podem ser definidas como "as atividades realizadas pelos gestores que continuamente coletam e analisam informações sobre o desempenho, que geram desafios e interligam metas de curto e de longo prazo, e que geram alto desempenho" (BLOOM; GENAKUS; SADUM; VAN REENEN, 2012, P. 4).

Embora se defenda nesse ensaio que as práticas de gestão precisam de uma gestão balanceada para ser fonte de desempenho, existem várias advertências para isso. Como ressaltam Bloom et al. (2012, p. 6), "há muitas práticas de gestão que são contingentes no ambiente das firmas

Estudos do CEPE [ISSN 1982-6729]. Santa Cruz do Sul, n. 45, p. 35-51, jan./jun. 2017. https://online.unisc.br/seer/index.php/cepe/index 
de negócios e produtos, como estratégia, finanças e marketing". O que esses autores recomendam é que o pesquisador se concentre num subconjunto restrito de práticas de gestão de base, em que as melhores práticas sejam mais prováveis de existir.

Como exemplo de boas práticas de gestão de empresas brasileiras, o banco de boas práticas do canal FQN cita uma série delas. Alguns exemplos de boas práticas de gestão são: avaliação de desempenho de fornecedores (AES Brasil); utilização do BSC no planejamento estratégico (Companhia de Eletricidade do Estado da Bahia - COELBA); plano de marketing (RL Sistemas de Higiene Ltda.); plano de desenvolvimento de recursos humanos no exterior (PETROBRAS: Área de Negócios de Abastecimento); Elaboração de cenários prospectivos (Embraer S.A).

A situação que é difundida é que as empresas ao adotarem boas práticas de gestão tendem a trilhar o caminho da excelência. Contudo, devido à ambiguidade causal (Barney, 1991) - que é a complexidade de fatores que podem levar uma firma a ter vantagem competitiva - é difícil isolar o efeito da gestão para se ter uma resposta precisa.

Para reduzir o problema da ambiguidade causal, pode ser uma estratégia de pesquisa viável separar em grupos de empresas aquelas que possuem características de uma gestão diferenciada. E se as que apresentarem melhor desempenho financeiro forem as que possuem uma gestão alinhada, coerente e consistente, então provavelmente o gerenciamento balanceado possa ser considerado uma capacidade organizacional.

Sendo possível definir gestão balanceada como capacidade organizacional, não é tão complexo definir práticas de gestão como recurso. A literatura do Strategic Management apresenta uma vasta lista de diferentes recursos que podem ser fonte de geração de vantagem competitiva. Convenientemente esta lista foi classificada em categorias de análise para facilitar um entendimento comum (HITT; IRELAND; HOSKISSON, 2008).

De maneira simplificada os recursos são classificados como de capital físico, capital humano e capital organizacional. Segundo Barney (1991, P. 3) "Recursos de capital organizacional incluem a estrutura formal das firmas, seu planejamento formal e informal, sistemas de controle e coordenação, bem como relações informais entre grupos de pessoas dentro da firma e entre a firma e seus stakeholders".

Como já foi citado não é problema definir práticas de gestão como recurso, porque pela clássica definição de Wernerfelt (1984, p.182), os recursos podem ser definidos de forma ampla como "qualquer coisa que possa ser pensada como uma força ou uma fraqueza da firma". A definição de Barney (1991, p. 3) corrobora com a anterior, ou seja, recurso "inclui todos ativos, capacidades, processos organizacionais, conhecimentos, dentre outros controlados pelas firmas, que as permitam conceber e implementar estratégias que promovam eficiência e efetividade".

Como o pressuposto fundamental da perspectiva da RBV é que o recurso e a capacidade organizacional são impulsionadores da geração de valor da firma, as capacidades precisam ser identificadas e categorizadas pela empresa, para em seguida ser investigada a sua validade estratégica (WILK, 2001). Por esse motivo a próxima seção apresenta uma forma de entender a proxy chamada gestão balanceada.

Estudos do CEPE [ISSN 1982-6729]. Santa Cruz do Sul, n. 45, p. 35-51, jan./jun. 2017. https://online.unisc.br/seer/index.php/cepe/index 


\subsection{Os Conceitos de Alinhamento, Coerência e Consistência}

No artigo clássico de Michael Porter (1996) chamado de "What is Strategy", o autor define estratégia como uma combinação de atividades. Transpondo a ideia de Porter para este ensaio teórico, a combinação de alinhamento, coerência e consistência é considerada uma capacidade organizacional, que é aqui conceituada como gestão balanceada. Ela diz respeito ao papel do gestor de administrar a estrutura, a estratégia e as competências organizacionais simultaneamente de forma alinhada, coerente e consistente para o alcance dos objetivos organizacionais.

Os conceitos de alinhamento, coerência e consistência estão muito ligados às escolas clássicas de administração de Taylor e Fayol e as teorias de sistemas e de planejamento de Ansoff (1979). A ideia que se tem é que desde o desenvolvimento do tema pela cena militar, os conceitos foram compreendidos pelos gestores, mas mesmo com a antiguidade deles, as organizações não os internalizam suficientemente como forma de alcançar os objetivos.

Alguns esforços foram realizados para acelerar esse processo de aprendizado. Para que fosse possível os gestores conceituarem e dirigirem a gerência estratégica da TI nas organizações, Henderson e Venkatraman (1993) desenvolveram um Modelo Estratégico de Alinhamento (MEA). No MEA, o alinhamento estratégico sofre influência do ambiente interno e externo a organização. Nele a estrutura administrativa, os processos e a as competências se alinham formando um subsistema organizacional. Esse subsistema interno se comunica com outros três subsistemas dentro da organização, formando uma integração funcional.

Mas esses autores só levam em consideração o alinhamento como forma dos gestores alcançarem os objetivos organizacionais. Com efeito, utilizando a ideia do modelo de Henderson e Venkatraman (1993), o que se propõe é que a coerência e a consistência são igualmente importantes para dirigir a gerência estratégica das empresas.

A ideia de alinhamento, coerência e consistência é mais importante que somente a ideia de alinhamento, uma vez que o todo é maior que a soma das partes. Essa máxima foi introduzida na administração pela abordagem sistêmica de Bertalanffy, que gradativamente substituiu a ideia de que a firma é um composto de recursos críticos isolados que servem como fatores de sucesso. Assim, a gestão de uma empresa será uma capacidade organizacional se ditada pela condição $T>D>U$ (Figura 2).

Onde $\mathrm{T}$ significa que a gestão organizacional apresenta simultaneamente as três características (alinhamento, coerência e consistência) na relação estratégia, estrutura e competência; D significa que a empresa possui simultaneamente duas das três características (alinhamento, coerência e consistência): e U significa que a empresa possui somente uma das três características (alinhamento, coerência e consistência) na relação estratégia, estrutura e competência. Como o todo é maior que a soma das partes, uma empresa que tenha as três condições aplicadas simultaneamente, terá mais balanceamento (equilíbrio) para promover práticas de gestão eficientes. Cabe aqui definir os termos que formam a gestão balanceada.

Alinhamento refere-se à ação ou resultado de colocar um conjunto de atividades, recursos materiais ou pessoas em linha reta, orientando segundo certa direção, desenho ou plano. É conseguir

Estudos do CEPE [ISSN 1982-6729]. Santa Cruz do Sul, n. 45, p. 35-51, jan./jun. 2017. https://online.unisc.br/seer/index.php/cepe/index 
vantagem competitiva desenvolvendo e sustentando um relacionamento simbiótico entre o negócio e o que é desenvolvido nas áreas organizacionais (BENZI, SOUZA NETO, ORLANDI; SOUZA, 2012). O alinhamento é importante, pois as empresas têm níveis hierárquicos e um desalinhamento na relação estratégia - estrutura - competência pode fazer as mudanças organizacionais demorarem a serem absorvidas pelos escalões de nível de gerência e operacional.

Figura 2 - Modelo de gestão balanceada na relação estratégia, estrutura, competência.

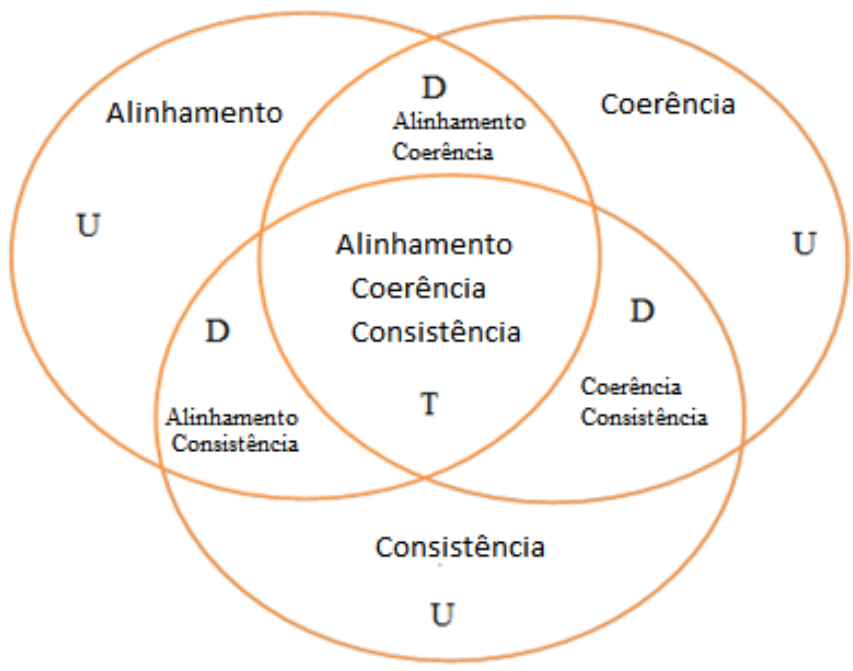

Fonte: Elaborada pelos autores.

Consistência é a característica de firmeza, aderência e resistência. Tanto a estratégia, como a estrutura organizacional e as competências devem ser consistentes para, ao serem implementados, alcançarem o objetivo da firma. Segundo Rumelt (1984), após a criação de diversas estratégias possíveis para o alcance dos objetivos, a estratégia não deve apresentar objetivos e politicas inconsistentes, sendo então a consistência um atributo para avaliação e escolha da estratégia a ser implementada.

No entendimento de Porter (1996, p. 71), "consistência torna a comunicação da estratégia com os acionistas, empregados e clientes mais fácil, ainda promove o aperfeiçoamento de uma mentalidade única na organização". Consistência também se refere à constância e regularidade. Ansoff (1979) relata a estratégia como um processo controlado, consciente e formal entre a empresa e o ambiente.

Coerência implica na relação lógica e harmônica entre ideias, atos e situações (planejamento e execução, por exemplo), com a condição de ausência de contradições ou paradoxos. Construir junto à alta administração da organização um consenso sobre o uso dos recursos, definindo as responsabilidades das unidades de negócios é uma forma de agir coerente do gestor.

Tendo-se definido gestão balanceada e enquadrado práticas de gestão como recurso organizacional, a próxima seção apresenta a construção da proposição da pesquisa.

Estudos do CEPE [ISSN 1982-6729]. Santa Cruz do Sul, n. 45, p. 35-51, jan./jun. 2017. https://online.unisc.br/seer/index.php/cepe/index 


\section{CONSTRUÇÃO DA PROPOSIÇÃO DA PESQUISA}

Se as empresas estão competindo num mesmo setor de atividades (nas mesmas condições de variáveis macro ambientais) e se uma firma gera melhor desempenho financeiro que outras, logo é porque elas são diferentes em pelo menos algum aspecto, e esse aspecto não pode ser facilmente adquirido ou a vantagem, em tese, será fugaz. A RBV introduziu a ideia de que os recursos não são adquiridos de forma perfeita no mercado, isso significa que por causa das falhas no mercado de fatores e pelos esforços de gestão, os recursos podem ser desenvolvidos internamente.

Nos últimos 50 anos diversas pesquisas têm sido realizadas para entender as práticas de gestão organizacional. No início de 1963 um grupo de professores da Escola de Administração de Empresas de São Paulo, da Fundação Getúlio Vargas, organizou um inquérito com o objetivo de conhecer de perto as dificuldades específicas enfrentadas pelas empresas de pequeno e médio porte no Brasil e as práticas administrativas então adotadas para resolvê-las, em vista do então precário conhecimento acerca dos métodos de gestão das empresas desse porte (MACHLINE, MOTTA; WEIL, 1996).

Os autores revelam que os empresários ignoravam as práticas de registros contábeis sistemáticos do governo e as consideravam mais como uma exigência das repartições fiscais do que como um instrumento de racionalização da administração, atitude que só dificultava a elaboração e o encaminhamento de solicitações de financiamento e crédito, resultava em fraca organização e administração, na dificuldade de obter acesso ao mercado de capitais e/ou dificuldades de obtenção de crédito, no relacionamento pessoal do empresário ou administrador com seus empregados e/ou clientes, e também dificuldade na participação e domínio relativo dos respectivos mercados (MACHLINE; MOTTA; WEIL, 1996).

Ou seja, os empresários não desenvolveram seus recursos de capital organizacional. Segundo Ribeiro Neto (2008), as firmas precisam refletir, refazer e implementar de forma permanente suas práticas de gestão, objetivando principalmente a manutenção e/ou a maximização de seus indicadores de desempenho.

Com o passar do tempo, a arena competitiva tornou-se mais dinâmica que a da década de 1960, mas atualmente as empresas ainda utilizam técnicas rudimentares e incompletas de gestão (Lima, 2008). Diversas pesquisas já investigaram o desempenho de empresas utilizando a gestão como recurso organizacional.

Teixeira e Loiola (2006) testaram o efeito das Práticas de Gestão de Pessoas (como cultura de aprendizagem, empowerment e trabalho em equipe), na influência de desempenho financeiro em 98 empresas de diversas indústrias (setores) no Brasil, contudo não houve relação estatisticamente significante entre as variáveis. Em contrapartida, Bloom et al. (2012) ao estudarem como e porque as práticas de gestão variam entre países Anglo-Saxões, bem como entre firmas e indústrias, verificaram que firmas que adotavam práticas de governança (monitoramento, metas bem definidas, e incentivos) eram mais lucrativas.

Lemos, Rocha, Costa e Lopes Junior (2011) investigaram o nível de gestão de empresas do setor de confecção. Os autores verificaram que todas as empresas apresentaram um nível de gestão

Estudos do CEPE [ISSN 1982-6729]. Santa Cruz do Sul, n. 45, p. 35-51, jan./jun. 2017. https://online.unisc.br/seer/index.php/cepe/index 
em suas áreas funcionais que variou de fraco a intermediário. Segundo os autores, os recursos organizacionais seriam os menos desenvolvidos e a justificativa é que os gestores de empresas de micro e pequeno porte são em sua grande maioria pragmáticos, e não despendem tempo nem recursos para investirem numa gestão estratégica, cujos resultados vêm em longo prazo.

A literatura da RBV já demonstrou que não são todos os recursos que promovem vantagem competitiva a uma empresa, inclusive alguns podem até reduzir a eficiência da firma. A ideia por traz do conceito de eficiência operacional de Porter (1996), por exemplo, é que se todas as empresas numa indústria tiverem as mesmas ferramentas gerenciais (sistema de qualidade total, benchmarking, competição baseada no tempo, terceirização, reengenharia, dentre outros), a estratégia não será necessária, pois os produtos/serviços de todas gerarão o mesmo valor aos clientes.

Da mesma forma pode-se argumentar que se todas as empresas numa indústria têm as mesmas práticas de gestão, nenhuma obterá desempenho superior sobre as outras se as estratégias e esforços internos não forem diferentes. Assim, as práticas de gestão são condição necessária, mas não suficiente à geração de desempenho financeiro diferenciado. Elas precisam então de algum esforço dos gestores que Ihes gerem eficiência. $O$ argumento é que o esforço dos gestores deve ser promover uma gestão alinhada, coerente e consistente com os objetivos da firma, assim, as práticas de gestão serão capazes de proporcionar efeitos positivos sobre o desempenho financeiro.

Como os esforços dos gestores são diretamente ligados à ação da organização, se a empresa possui uma gestão que seja alinhada, coerente e consistente na elaboração e implementação das estratégias, estruturas e competências organizacionais, ela poderá configurar e reconfigurar seu ambiente interno (pessoas, processos, procedimentos) de forma consciente e constante (RIBEIRO NETO, 2008). Assim, a proposição da pesquisa é que práticas de gestão de empresas com gestão balanceada podem exercer efeito positivo no desempenho financeiro.

\section{CONSIDERAÇÕES FINAIS E APLICAÇÃO EMPÍRICA}

O objetivo deste ensaio foi gerar a proposição de que as práticas de gestão e o esforço despendido para manter o equilíbrio da gestão organizacional (gestão balanceada), são condições preditoras de desempenho financeiro superior. Acredita-se que o impacto do argumento aqui proposto sobre o cotidiano empresarial, aconteça sob a condição dos gestores respeitarem o desenvolvimento do gerenciamento estratégico. Isso ajudaria a reduzir a prática exaustiva de investimentos em práticas de gestão copiadas de outras organizações sem nenhuma adaptação, principalmente das pequenas empresas pelas grandes empresas, dando lugar ao pensar sobre a gestão estratégica.

Não foi a intenção deste ensaio insinuar que as práticas de gestão são irrelevantes nos atuais cenários de mercado, mas que estas não gerarão o efeito esperado se não forem antecedidas por uma gestão balanceada. Sabendo quais práticas de gestão geram efeito sobre o faturamento, os gestores podem então criar uma propensão à continuidade de adoção dessas mesmas práticas, de acordo com os resultados percebidos, gerando um ciclo crescente de adoção e sustentação de novas práticas (TEIXEIRA; LOIOLA, 2006).

Estudos do CEPE [ISSN 1982-6729]. Santa Cruz do Sul, n. 45, p. 35-51, jan./jun. 2017. https://online.unisc.br/seer/index.php/cepe/index 
Para aplicação empírica do ensaio, sugere-se que a abordagem metodológica adotada seja de natureza quantitativa e a pesquisa seja tratada como um projeto de levantamento. "Um projeto de levantamento dá uma descrição quantitativa ou numérica de tendências, atitudes ou opiniões de uma população ao estudar uma amostra dela" (CRESWELL, 2007, p.161). Os passos sugeridos são:

Passo 1) desenvolver um roteiro composto de perguntas objetivas e diretas referentes à utilização das práticas de gestão e que revelem detalhes sobre alinhamento, coerência e consistência nas relações entre estratégia, estrutura e competências organizacionais;

Passo 2) assuntos utilizados para serem analisados sob o foco da estratégia pode ser: alianças estratégicas, terceirização, metas e objetivos, ambiente e mercado, recursos internos, meio ambiente e sustentabilidade. Os assuntos utilizados para serem analisados sob o foco da competência podem ser: recursos internos, know-how, tecnologia, especialização, pessoas; sob o foco de estrutura os assuntos podem ser: prédio, estrutura organizacional, equipamentos/instalações, marca e imagem, sistemas administrativos e materiais e insumos.

Passo 3) realizar uma validade de face e de conteúdo do instrumento de pesquisa (NETEMEYER; BEARDEN; SHARMA, 2003);

Passo 4) apresentar aos entrevistados recorte dos conceitos de estratégia, estrutura e competência como os que se encontram no Quadro 1. Por meio dessa ação de pesquisa, os entrevistados podem entender melhor as perguntas, repensando as suas práticas e formas de gestão para respondê-las.

Quadro 1 - Referência Conceitual.

\begin{tabular}{|l|l|}
\hline \multirow{5}{*}{ Estratégia } & $\begin{array}{l}\text { A estratégia é um caminho a ser seguido, determina um padrão de tomada de } \\
\text { decisão. Estratégia pode ser definida como processo controlado, consciente, e formal } \\
\text { das organizações (ANSOFF, 1979). Ela é "padrão fundamental de recursos presentes } \\
\text { e a implementação de recursos planejados na sua interação com o ambiente, que } \\
\text { indica como uma organização ira alcançar seu objetivo" (HOFER; SCHENDEL, 1978, } \\
\text { P.25). }\end{array}$ \\
\hline \multirow{5}{*}{ Estrutura } & $\begin{array}{l}\text { A estrutura define as tarefas e as responsabilidades no âmbito do trabalho, ela deve } \\
\text { estar provida de meios de coordenação das mesmas. Sabe-se que a estrutura } \\
\text { organizacional influencia e é influenciada diretamente pela estratégia da empresa. } \\
\text { Não existe uma estrutura organizacional acabada e nem perfeita para as empresas, } \\
\text { mas aquela que se adapte adequadamente às mudanças. }\end{array}$ \\
\hline \multirow{5}{*}{$\begin{array}{l}\text { Competência } \\
\text { organizacional }\end{array}$} & $\begin{array}{l}\text { As competências devem agregar valor econômico para a organização e valor social } \\
\text { para o indivíduo (FLEURY; FLEURY, 2011). As competências gerenciais estão } \\
\text { ligadas aos gestores (diretores, gerentes, chefes, etc.) (PICCHIAl, 2007). As } \\
\text { atuando na busca de seus objetivos e metas (PRAHALAD; HAMEL, 1990). } \\
\text { Competência é um conjunto de habilidades e tecnologias, e não uma única habilidade } \\
\text { e tecnologia isolada que permitam a uma empresa oferecer determinado benefício as } \\
\text { suas partes interessadas. }\end{array}$ \\
\hline
\end{tabular}

Fonte: Elaborado pelos autores.

Estudos do CEPE [ISSN 1982-6729]. Santa Cruz do Sul, n. 45, p. 35-51, jan./jun. 2017. https://online.unisc.br/seer/index.php/cepe/index 
Passo 5) a variável dependente (desempenho financeiro) pode ser acessada pelo Retorno sobre os Ativos (ROA) das empresas, ou por medidas mais simples, como a receita operacional bruta, por exemplo.

Para operacionalizar a análise de dados a estratégia conhecida como Análise Qualitativa Comparativa, ou QCA (Qualitative Comparative Analysis), desenvolvida por Charles Ragin (Ragin, 2008; Rihoux \& Ragin, 2009), é apropriada. A QCA é baseada na álgebra Booleana e o método de análise csQCA é a técnica de pesquisa orientada à comparação de casos mais simples, porque usa linguagem binaria (1,0) (Marx; Dusa, 2011). Para mensurar o que é originalmente nominal, a QCA usa códigos binários de valores para indicar que $1(\operatorname{sim})$ o caso é presente e participa do conjunto resposta, e 0 (não) para indicar que o caso não participa do conjunto resposta (Ragin, 2008).

Seguindo a orientação teórica do modelo conceitual desenvolvido para esse ensaio (Figura 1), os pesquisadores elaboraram as condições causais que deveriam estar presentes na ocorrência de desempenho financeiro superior. A equação 1 diz que desempenho financeiro é resultado da presença de práticas de gestão combinada com gestão balanceada.

Desempenho financeiro $=$ práticas de gestão * gestão balanceada $(1)$

Muitas vezes a estratégia, a estrutura e as competências da organização são desenhadas por meio do ciclo de vida da firma e das experiências dos indivíduos que nelas trabalham. Estas variáveis são importantes e resultam das práticas adquiridas com seu próprio negócio, e se constituem num campo de conhecimento. Elas pertencem aos gestores no exercício eficaz e eficiente de suas atribuições, assim como no cumprimento de seus papéis organizacionais. Sugere-se que os sujeitos da pesquisa sejam os proprietários (principais acionistas, sócios-gestores) e os funcionários de nível tático (os gestores não sócios das empresas), a fim de se obter uma visão ampla da real situação da empresa evitando viés nas respostas. A escolha desses sujeitos é justificada pelo fato de que, na maioria das organizações, é passível de ser identificado um conjunto de objetivos traçados, seja de forma explícita ou não, assim, através da história vivida nestas empresas, as principais pessoas que nelas trabalham são capacitadas a responder sobre as peculiaridades da organização.

\section{REFERÊNCIAS}

ANSOFF, H. I. Estratégia empresarial. São Paulo: McGraw Hill, 1979.

BARNEY, J. B. 'Firm resources and sustained competitive advantage'. Journal of Management, v. 17, P. 99-120, 1991.

BARNEY, J. B. 'Organizational culture: can it be a source of sustained competitive advantage?' Academy of Management Review, v. 11, P. 656-65, 1986.

BARNEY, J. B. Resource based theories of competitive advantage: A ten year retrospective on the resource based view. Journal of management, v. 27. P. $643-650.2001$

Estudos do CEPE [ISSN 1982-6729]. Santa Cruz do Sul, n. 45, p. 35-51, jan./jun. 2017. https://online.unisc.br/seer/index.php/cepe/index 
BENZI, D. M.; SOUZA NETO, J.; ORLANDI, T. R. C.; SOUZA Jr. R. T. Governança de tecnologia da informação: facilitadora na estratégia organizacional. In: IX Simpósio de Excelência em Gestão e Tecnologia - SEGeT, Rio de Janeiro. Anais... Rio de Janeiro, 2012.

BLOOM, N; GENAKOS, C; SADUN, R; VAN REENEN, J. Management practices across firms and countries. Working paper. Disponível em: <http://www.nber.org/papers/w17850>. Acesso: 16 Nov. 2016.

CHANDLER, A. Strategy and structure. MA: MIT Press, 1962.

COASE, R. H. The Nature of the Firm. Economica, v. 4, p. 386-405. 1937.

CRESWELL, J. Projeto de pesquisa: métodos qualitativo, quantitativo e misto. 2. ed. Porto Alegre: Bookman, 2007.

DOSI, G. Technological paradigms and technological trajectories, Research Policy, v.11, P.147-162, 1982.

DOSI, G.; NELSON, R.; WINTER, S. The Nature and Dynamics of Organizational Capabilities. Oxford: Oxford University Press, 2000.

FLEURY, A.; FLEURY, M.T.L. Estratégias empresariais e formação de competências: um quebracabeça caleidoscópico da indústria brasileira. 3ª Ed. - 6ª reimp. - São Paulo: Atlas, 2011.

HELFAT, C.E; PETERAF, M. A. The dynamic resource-based view: capabilities life cycles. Strategic Management Journal, v. 24, n.10, p. 997-1010, 2003.

HENDERSON, J. C.; VENKATRAMAN, N. Strategic alignment: leveraging information technology for transforming organizations. IBM Systems Journal, v. 32, n. 1, p. 4-16, 1993.

HITT, M. A; IRELAND, R. D; HOSKISSON, R, E. Administração Estratégica: Competitividade e Globalização. São Paulo: Cengage Learning, 2008.

HOFER, C.W; SCHENDEL, D. Strategy formulation: Analytical concepts. West Publishing. St.Paul, 1978.

KAPLAN, R. S., NORTON, D. P. Mapas estratégicos - Balanced Scorecard: convertendo ativos intangíveis em resultados tangíveis. 10ªํㅡ. ed. Rio de Janeiro: Elsevier, 2004.

KOR, Y. Y; MAHONEY, J. T. Edith Penrose's (1959) Contributions to the Resource-based View of Strategic Management. Journal of Management Studies. v.41, n.1, 2004.

LANGLOIS, R.N. Cost-benefit analysis, environmentalism, and rights. The Cato Journal, v. 2, n.1, p. 279-300,1982.

LEMOS, A. Q.; PICCHIAI, D. E. Gestão Balanceada e Práticas de Gestão: Um Estudo Sobre Suas Influências no Desempenho Financeiro. In: VI Encontro de Estudos em Estratégia, 2013, Bento Gonçalves/RS. Anais... Bento Gonçalves/RS: 3Es, 2013.

LEMOS, A, Q; ROCHA, M; COSTA, J. P. S.; LOPES JUNIOR, E. P. Gerenciando os Caminhos para Mudança: um Estudo sobre o Ambiente Interno de Confecções Cearenses. Sociedade, Contabilidade e Gestão, Rio de Janeiro, v. 6, n. Especial, p. 84-100, 2011.

LIMA, E. Estratégica de pequenas e médias empresas: Uma revisão. In: V Encontro de Estudos sobre Empreendedorismo e Gestão de Pequenas Empresas - EGEPE, São Paulo. Anais... São Paulo, 2008.

MACHLINE, C.; MOTTA, I. S.; WEIL, K. E. A Administração da produção na pequena empresa brasileira. Fundação Getulio Vargas, Rio de Janeiro, 1996.

Estudos do CEPE [ISSN 1982-6729]. Santa Cruz do Sul, n. 45, p. 35-51, jan./jun. 2017.

https://online.unisc.br/seer/index.php/cepe/index 
MAHONEY, J. T. 'The management of resources and the resource of management'. Journal of Business Research, v. 33, n. 2, p. 91-101, 1995.

MAHONEY, J. T.; PANDIAN, J. R. The resource-based view within the conversation of strategic management. Strategic Management Journal, v. 13, n. 5, P. 363-380, Jun. 1992.

MARX, A.; DUSA. A. Crisp-Set Qualitative Comparative Analysis (csQCA): Contradictions and consistency benchmarks for model specification, Methodological Innovations Online, v. 6, n. 2, p. 103-148. 2011.

MINTZBERG, H; AHLSTRAND, B; LAMPEL, J. Safári de Estratégia: Um Roteiro Pela Selva do Planejamento Estratégico. Porto Alegre: Bookman, 2000.

NETEMEYER, R. G.; BEARDEN, W. O.; SHARMA, S. Scalling procedures: issues and applications. Thousand Oaks: Sage, 2003.

PENROSE, E. T. The Theory of the Growth of the Firm. New York: John Wiley, 1959.

PETERAF, M. A. "The Cornerstones of competitive Advantage: A Resource-Based View", in Foss, Nicolai J. (ed.), Resource Firms and Strategies, Oxford University Press, New York, p.187203, 1993.

PICCHIAI, D. Competências gerenciais: caso de um hospital público. Fundap, 2007.

PORTER, M. E. What is strategy? Harvard Business Review, v. 74, n. 6, p.61-78, 1996.

PRAHALAD, C. K.; HAMEL, G. The Core Competence of the Corporation. Harvard Business Review, P. 3-15, May/June, 1990.

PRIEM, R. L.; BUTLER, J. E. Is the resource-based "view" a useful perspective for strategic management research? Academy of Management Review, v. 26, n. 1, p. 22-40, 2001.

RAGIN, C. C. Redesigning Social Inquiry - Fuzzy Sets and Beyond. Chicago: University of Chicago Press, 2008

REZENDE, J. F. C; AVILA, M; MAIA, R. S. Geração e gestão do valor por meio de métricas baseadas nas perspectivas do capital intelectual. Revista de Administração, São Paulo, v.47, n.1, p.51-67, 2012.

RIBEIRO NETO, A. B. Fatores que impactam o desempenho de pequenas empresas. 2008, $379 f$. Tese (Doutorado em engenharia da produção). Centro de Pós-graduação em Engenharia de Produção da Universidade Federal do Rio de Janeiro. Rio de Janeiro: UFRJ, 2008.

RICARDO, D. 1817. On the Principles of Political Economy and Taxation. Variorum edition in P. Sraffa, ed., Works \& Correspondence of David Ricardo, Vol. I. Cambridge: Cambridge University Press, 1951.

RIHOUX, B., \& RAGIN, C. C. Configurational Comparative Methods. Thousand Oaks: Sage Publications, Inc, 2009.

RUMELT, R. P. Towards a strategic theory of the firm. In Competitive Strategic Management. Ed. Richard B. 1984. Lamb. Engelwood Cliffs, NJ: Prentice-Hall, 566-570.

RUMELT, R. P., SCHENDEL, D.; TEECE, D. J., Strategic management and economics. Strategic Management Journal, v. 12. P. 5-29. 1991.

SCHUMPETER, J., Capitalism, Socialism, and Democracy. New York: Harper \& Row, 1942.

SELZNICK, P. Leadership in Administration: A Sociological Interpretation. Row, Peterson and Co., 1957.

Estudos do CEPE [ISSN 1982-6729]. Santa Cruz do Sul, n. 45, p. 35-51, jan./jun. 2017.

https://online.unisc.br/seer/index.php/cepe/index 
TEECE, D.; PISANO, G.; SCHUEN, A. Dynamic Capabilities and Strategic Management. Strategic Management Journal, v. 18, n. 7, p. 509-533, 1997.

TEIXEIRA, J. C. A.; LOIOLA, E. Práticas Inovadoras de Gestão de Pessoas e Desempenho Organizacional no Brasil. In: Encontro da Associação Nacional de pós-graduação e Pesquisa em Administração, 30, 2006, Salvador/BA. Anais... Salvador/BA: ANPAD, 2006.

WERNERFELT, B. A resource-based view of the firm. Strategic Management Journal, v. 5, p. 171180, 1984.

WILK, E. O. Resource-Based View e Manufatura, Uma Conversação Estratégica. Anais... XIII Encontro Nacional da Engenharia da Produção - ENEGEP, Santa Catarina, 2001. Disponível: <http://www.abepro.org.br/biblioteca/ENEGEP2001_TR73_0349.pdf>. Acesso em: 16 dez.2012.

WILLIAMSON, O. E. Comparative Economic Organization: The Analysis of Discrete Structural Alternatives, Administrative Science Quarterly, v. 36. P. 269-296. 1991.

WILLIAMSON, O. E. The Economic Institutions of Capitalism. New York: The Free Press, 1985. 